\title{
Reduced Graphene Oxide/Nickel Oxide/Polyaniline: Preparation and Properties Investigation as Supercapacitor Electrode Material
}

\author{
Yunshan Bai ${ }^{1,2, *}$, Guoxiang Sun ${ }^{1, *}$, Song Chen ${ }^{1}$, Lude $\mathrm{Lu}^{2}$, Jianchun Bao ${ }^{2}$ \\ ${ }^{1}$ College of Chemistry and Chemical Engineering, Yancheng Institute of Technology, Yancheng \\ 224003, P. R. China \\ ${ }^{2}$ Key Laboratory for Soft Chemistry and Functional Materials of Ministry of Education, Nanjing \\ University of Science and Technology, Nanjing 210094, P. R. China \\ *E-mail: bys@ycit.edu.cn, zgdsgx@126.com
}

doi: $10.20964 / 2017.01 .20$

Received: 18 September 2016 / Accepted: 24 November 2016 / Published: 12 December 2016

\begin{abstract}
Reduced graphene oxide/nickel oxide/polyaniline (GNP) was prepared by a two-step method. First, the reduced graphene oxide/nickel oxide composite material is prepared, and then the conductive polyaniline is loaded on the surface. The electrode materials were characterized by XRD, Raman spectra, TEM and HRTEM. Adopting a three electrode test system, the electrochemical properties of the materials were measured by cyclic voltammetry, constant current charge/discharge and AC impedance. The results showed that the characteristic peaks of graphene oxide were not detected in the XRD spectra of the reduced graphene oxide/nickel oxide composite, which shows that graphene oxide films with good dispersity was obtained in the process of the composite. High resolution transmission electron microscopy shows that the reduced graphene oxide / nickel oxide/polyaniline with a rough surface, indicating that the polyaniline was successfully loaded on the reduced graphene oxide/nickel oxide surface. The specific capacitance of GNP is $638 \mathrm{Fg}^{-1}$. Under the current density is $500 \mathrm{~mA} \mathrm{~g}^{-1}$, the specific capacitance maintained $100 \%$ after 1000 cycles while it reduced only $9 \%$ after 5000 cycles.
\end{abstract}

Keywords: Graphene oxide, nickel oxide, polyaniline, electrode material, three element composites

\section{FULL TEXT}

(C) 2017 The Authors. Published by ESG (www.electrochemsci.org). This article is an open access article distributed under the terms and conditions of the Creative Commons Attribution license (http://creativecommons.org/licenses/by/4.0/). 